\title{
Miguel Hidalgo: Ilustrado Consumado ${ }^{1}$
}

\author{
Miguel Hidalgo, Accomplished Erudite \\ Miguel Hidalgo, Ilustrado Consumado
}

\author{
Alberto Saladino García ${ }^{2}$ \\ Universidad Autónoma del Estado de México - México \\ asaladinog@uaemex.mx
}

Recepción: 09/04/2013

Evaluación: 19/07/2013

Aceptación: 15/05/2014

Artículo de Reflexión

\section{RESUMEN}

En este artículo se explica la génesis del proceso independentista en México con base en el análisis del documento mediante el cual Miguel Hidalgo argumentó y justificó su proceder político. Para el efecto, se dilucida la identificación de las ideas ilustradas apropiadas y cultivadas por el padre de la patria mexicana, para explicar su fomento y praxis en su loable propósito de separar a la Nueva España del dominio de la metrópoli, al generar el diseño de la nueva nación fundada en un espacio territorial específico y en el despliegue de una cultura propia para alumbrar la consolidación de la autoconciencia de la comunidad mexicana; aspectos con los cuales se construiría el Estado-nación mexicano. El proceso de análisis consistió en destacar el contexto sociopolítico de la Nueva España y las singularidades de su ambiente de renovación cultural durante los últimos sesenta años de vida virreinal, y con base en ellos, se explica la formación intelectual de Miguel Hidalgo, para luego efectuar la exégesis del texto y contrastar su contenido con los valores propalados por la Ilustración, evidenciando las contradicciones inherentes para corroborar su identificación de ilustrado consumado, esto es, de paradigma de tal corriente de pensamiento por haber sido capaz de fusionar las expectativas políticas del sector social de los criollos con las ideas del movimiento cultural de la Ilustración y, sobre todo, por haberlas llevado a la práctica al iniciar la lucha independentista desplegando, como ningún otro héroe mexicano, una verdadera praxis revolucionaria.

$1 \quad$ Esta investigación se realizó en la Facultad de Humanidades de la Universidad Autónoma del Estado de México, sin apoyo económico.

2 Doctor en Estudios Latinoamericanos. Profesor investigador de la Facultad de Humanidades de la Universidad Autónoma del Estado de México, Paseo Universidad s/n, esquina Paseo Tollocan, Ciudad Universitaria, Toluca, México. 
Palabras clave: Revista Historia de la Educación Latinoamericana, criollo, ilustrado, independencia, Miguel Hidalgo, revolución.

\begin{abstract}
This article describes the genesis of the independence process in Mexico, there is an analysis of the document by which Miguel Hidalgo argued and justified his political proceeding. And thus, the identification of appropriate and cultivated ideas of the father of the Mexican nation. In order to explain the its development and praxis in his laudable purpose of separating the New Spain of the domain of the metropolis, he enlightened ideas to design the new nation founded in a specific territorial space and in the deployment of a proper culture to give the light in the consolidation of selfconsciousness of the Mexican community; aspects with which would be built the nation-state mexican.
\end{abstract}

The analysis process centers in taking into account the the sociopolitic context o the New Spain and the particularities of the cultural renwement environment of the last 60 years of viceroyship and with this basisthere is the explanation of the intellectual development of Miguel Hidalgo, then to carry the exegesis of the text out and to constat its content with the values spread out by the Enlightenment, demonstrating the inherent contradictions to corroborate the identification of illustrated perfectly,this is, of paradigm of such a current of thought for having been capable of fusing the political expectations of the social sector of the Creoles with the ideas of the cultural movement of the Enlightenment and, and, especially, for having taken them to the practice on having initiated the independence revolution opening, as no other Mexican hero, a real revolutionary praxis.
Key words: Journal History of the LatinAmerican Education Creole, Englighned, independence, Miguel Hidalgo, revolution.

\section{RESUMO}

Neste artigo se explica a gênese do processo independentista no México com base na análise do documento em que Miguel Hidalgo argumentou e justificou seu proceder político. E, para isso, se elucida a identificação das ideias ilustradas apropriadas e cultivadas pelo pai da pátria mexicana, para explicar seu fomento e práxis em seu louvável propósito de separar a Nova Espanha do domínio da metrópole, ao traçar o desenho da nova nação fundada em um espaço territorial específico e na implantação de uma cultura própria para iluminar a consolidação da autoconsciência da comunidade mexicana; aspectos com os quais se construirá o Estado-nação mexicano. O processo de análise consistiu em destacar o contexto sociopolítico da Nova Espanha e as singularidades de seu ambiente de renovação cultural durante os últimos sessenta anos de vida vice-real, e com base nisto se explica a formação intelectual de Miguel Hidalgo, para logo efetuar a gênese do texto e contrastar seu conteúdo com os valores propalados pela ilustração, evidenciando as contradições inerentes para corroborar sua identificação de ilustrado consumado, isto é, de paradigma de tal corrente de pensamento por haver sido capaz de fundir as expectativas políticas do setor social dos crioulos com as ideias do movimento cultural da ilustração e, sobre tudo, como nenhum outro herói mexicano, uma verdadeira práxis revolucionária.

\section{Palavras-chave: Revista História da Educação Latino-americana, crioulo, ilustrado, independência, Miguel Hidalgo, Revolução.}




\section{INTRODUCCIÓN}

Como parte de la conmemoración del bicentenario del inicio de las luchas de independencia en los países latinoamericanos, me parece pertinente atender la génesis del proceso independentista en México con base en el análisis de uno de los documentos de Miguel Gregorio Antonio Ignacio Hidalgo y Costilla Gallaga Mandarte Villaseñor, con el propósito de clarificar el problema: ¿cuáles fueron las ideas y valores de la Ilustración que lo guiaron en su acción revolucionaria?

De modo que el objetivo principal de este estudio se centra en la identificación de las ideas ilustradas, apropiadas y cultivadas por el padre de la patria mexicana, para explicar su fomento y praxis en su loable propósito de separar a la Nueva España del dominio de la metrópoli, al generar el diseño de la nueva nación fundada en un espacio territorial específico y en el despliegue de una cultura propia para alumbrar la consolidación de la autoconciencia de la comunidad mexicana; aspectos con los cuales se construiría el Estado-nación mexicano.

El proceso de investigación fue guiado por el método dialéctico cuya aplicación consistió en destacar el contexto sociopolítico de la Nueva España y las singularidades de su ambiente de renovación cultural durante los últimos sesenta años de vida virreinal, y con base en ellos, explicar la formación intelectual de Miguel Hidalgo, para luego pasar a efectuar el análisis del texto que escribió y contrastar su contenido con los valores propalados por la Ilustración, evidenciando las contradicciones inherentes para corroborar su identificación de ilustrado consumado, esto es, de paradigma de tal corriente de pensamiento por haber sido capaz de fusionar las expectativas políticas del sector social de los criollos con las ideas del movimiento cultural de la Ilustración y, sobre todo, por haberlas llevado a la práctica al iniciar la lucha independentista desplegando, como ningún otro héroe mexicano, una verdadera praxis revolucionaria.

Los resultados de la investigación permiten probar que Miguel Hidalgo fue hijo de su tiempo, de una época en que las ideas de la Ilustración sustentaron la reforma sobre la concepción del hombre y de la sociedad, las cuales sirvieron de pauta para coadyuvar a ella en la Nueva España y que asumió totalmente su responsabilidad al estar dotado de los elementos teóricos fundamentales del periodo de renovación cultural; por eso, lo identifico como un ilustrado consumado.

\section{Semblanza}

Miguel Gregorio Antonio Ignacio Hidalgo y Costilla Gallaga nació el 8 de mayo de 1753 en la Hacienda de San Diego Corralejo, jurisdicción de Pénjamo, actual estado de Guanajuato. Sus padres fueron Cristóbal Hidalgo y Costilla Gallaga, nativo de Tejupilco, hoy Estado de México, y de Ana María Gallaga Mandarte Villaseñor, de Pénjamo. Murió fusilado el 30 de julio de 1811 en Chihuahua.

Su educación básica la cursó en la Hacienda de Corralejo, donde su padre era el administrador; luego pasó a Valladolid, ciudad en la que realizó parte de sus estudios superiores: del 20 de octubre de 1767 al 20 de febrero de 1770 llevó cursos de Artes en el Colegio de San Nicolás Obispo y también hizo cursos en el Colegio de San Francisco Xavier, de la orden de los jesuitas. Luego pasó a la ciudad de México, donde se graduó como Bachiller en Artes en la Real y Pontificia Universidad de México el 30 de marzo de 1770; de regreso a Valladolid, cursó 
Teología en el Colegio de San Nicolás Obispo, entre 1771 y 1773, y el 12 de abril de este último año obtuvo el grado en la Real y Pontificia Universidad de México. ${ }^{3}$

Existe un documento de su propia autoría donde resume su formación intelectual, del cual transcribo algunas partes para completar informaciones relativas a su vida académica:

Primeramente, aprendió Gramática y Retórica en dos años, teniendo en ambas las primeras públicas oposiciones.

Estudió Filosofía, en donde fue presidente de la Academia de sus condiscípulos, tuvo un acto de Física y lo premió su Maestro con el primer lugar.

Después de graduado en esta facultad siguió Teología...

Graduado en esta facultad, sustentó un acto de las Prelecciones del padre Serry...

Ha sido Pasante de Gramáticos, Presidente de la Academia de Filósofos y Teólogos...

Fue Catedrático de Mínimos y Menores, y Filosofías...

Sustituyó por mucho tiempo la Cátedra de Escolástica...

Ha predicado varios sermones Panegíricos, morales y doctrinales...

Hizo dos disertaciones sobre el verdadero método de estudiar Teología Escolástica, una latina y otra castellana...

Presidió dos actos mayores...

Tradujo la Epístola del Doctor Máximo San Jerónimo a Nepociano...

... es actualmente Catedrático de Prima de Teología... ${ }^{4}$

Como puede apreciarse, sus estudios los realizó con especial dedicación y su actividad docente la desarrolló con total esmero y aplicación. Los temas de sus estudios abarcaron contenidos de Gramática, Filosofía, Física, Música, Retórica, Teología, y aprendió y dominó varios idiomas: latín, francés, náhuatl, otomí y purépecha. O sea, tuvo una buena formación en los aspectos predominantes, sobre todo, del ámbito de la cultura escolástica, pero traspasó esa concepción por el espíritu crítico que adoptó, así como por su apego a la lectura, con lo que se hizo de informaciones sobre aspectos de la cultura moderna, como de la cosmovisión de los hoy llamados "pueblos originarios". Su sólida formación educativa lo dotó de los elementos teóricos para asumir una posición de avanzada intelectualmente.

Esa formación la enriqueció con su apego a la universidad de la vida; en primer lugar, con su desempeño como docente en la enseñanza de la Gramática Latina y de Retórica (1779), de Filosofía (1781), de Teología Escolástica (1783) y de Prima de Teología (1788) en el Colegio de

3 Moisés Guzmán Pérez, Miguel Hidalgo y el gobierno insurgente en Valladolid (Morelia: Universidad Michoacana de San Nicolás de Hidalgo, 1996), 36-37 y Bernabé Navarro, Cultura mexicana moderna en el siglo XVIII (México: Universidad Nacional Autónoma de México, 1983), 210-211.

4 Transcrito por Navarro, Cultura mexicana, 209-210. 
San Nicolás Obispo, ${ }^{5}$ por lo cual su labor de profesor reforzó el dominio de los temas caros a esas disciplinas e, incluso, le permitieron manifestar sus actitudes renovadoras. Por ejemplo, ante la convocatoria del deán de la catedral Joseph Pérez Calama, escribió la Disertación sobre el verdadero método de estudiar teología escolástica en 1784, donde propuso sustituir el método de enseñanza de la Teología. Luego adquirió responsabilidades directivas al desempeñar en dicho colegio las funciones de tesorero (1787), secretario (1788), vicerrector (1788) y rector (1792).

Sus actitudes intelectuales heterodoxas, por ejemplo, sus puntos de vista críticos en temas teológicos y por su conducta liberal, llevaron a que se le acusara en diversas ocasiones ante el Tribunal de la Inquisición: la primera fue hecha por el fraile mercedario Joaquín Huesca el 16 de julio de 1800; poco tiempo después, se le volvió a denunciar, en 1801, junto con el obispo Manuel Abad y Queipo, que también gustaba de la lectura de libros prohibidos. ${ }^{6}$ Ciertamente, entonces, no fue condenado.

En el mes de octubre de 1803, fue adscrito al Curato de la Congregación de los Dolores. Allí se ganó a la feligresía enseñándoles métodos para introducir nuevas actividades económicas, entre ellas, el cultivo de la uva; propagó el plantío de moreras, la cría de abejas y la apertura de talleres para enseñar la producción de seda, loza, ladrillos y sobre curtiduría. Su tiempo libre lo diversificó en la lectura y traducción de textos del francés, cuyos aprendizajes los visibilizaba en reuniones en su casa como en encuentros con criollos con semejantes intereses, en ciudades cercanas como Guanajuato, lo que, según relató Lucas Alamán, "hacía que fuese a ella frecuentemente y permaneciese largas temporadas, lo que me dio ocasión de verlos y tratarlo muy de cerca". ${ }^{7}$ En San Miguel el Grande, entró en contacto con Ignacio Allende y Juan Aldama, y en Querétaro, coincidió con Josefa Ortiz, quienes se convirtieron en los principales promotores de la lucha por la independencia.

Esas conductas heterodoxas de Miguel Hidalgo son las que preocuparon a los realistas y, por ello, las denuncias sobre su persona persistieron. Fue el franciscano Miguel Bringas quien presentó otra denuncia contra él ante el Tribunal de la Inquisición en 1809. Las denuncias se intensificaron con el inicio y durante la lucha armada que comandó, por lo que se le persiguió hasta su detención y fusilamiento.

Miguel Hidalgo entró en contacto con los planteamientos de una nómina amplísima de pensadores americanos y europeos, de todos los intereses gnoseológicos y las más variadas tendencias culturales e ideológicas. De ella da cuenta la lista que sigue: Aristóteles, Manuel Abad y Quipo, Francisco Javier Alegre, José Antonio Alzate, José Ignacio Bartolache, Juan Lorenzo Berti, Carlos René Bilbart, Conde de Buffon, Jacques-Benigne Bossuet, Melchor Cano, Marco Tulio Cicerón, Francisco Javier Clavigero, Jean Antoine Condorcet, Demóstenes, Juan Benito Díaz de Gamarra, Denis Diderot, Benito Jerónimo Feijoó, Claude Fleury, Honorato Furnely, Antonio Genovesi, Juan Gerson, Vicente Luis Gotti, Ignacio Jacinto Amal de Gravesson, La Fontaine, Claudio Adriano Helvecio, Pedro Lombardo, Molière, Montesquieu, Alexandre Natal, José Pérez Calama, Dionisio Petavio, Gayot de Pitabal, Jean Baptiste de Poquelín, Jean Racine, Guillermo Tomás Francisco Raynal, Charles Rollin, Juan Jacobo Rousseau, Jacobo Jacinto Serry, Santo Tomás, Jacques Vaniére, Luis Antonio Verney “el Barbadiño", Voltaire...

\section{Ibíd., 211.}

6 María del Carmen Rovira Gaspar, Una aproximación a la historia de las ideas filosóficas en México. Siglo XIX y principios del XX (México: Universidad Nacional Autónoma de México, 1997), 57-58.

7 Lucas Alamán, “Semblanza de los iniciadores de la independencia”, en Antología de lecturas de historia de México, ed. Martha Celada Castillo y Ruvalcaba (México: Universidad Nacional Autónoma de México, 1995), 67. 
Asimismo conoció informaciones sobre la lucha de independencia de los Estados Unidos y la Revolución francesa y los documentos de sus respectivos triunfos: las constituciones de Carolina del Norte, de Massachusets, de Delawere, de Pennsylvania; la Declaración de Derechos del Pueblo de Virginia de 1776, la Declaración de los Derechos del Hombre y del Ciudadano de 1789 y la Enciclopedia.

Respaldado en ese bagaje cultural, influido por algunas de las ideas de la Ilustración y comprometido con los sectores sociales excluidos, claro exponente del criollismo, tomó la decisión de encabezar la lucha por la independencia que, de manera triunfal, inició el 16 de septiembre de 1810, lo que le permitió instrumentar algunos de los valores de la época moderna como la igualdad, la justicia, la libertad y la soberanía, según lo prueban los documentos que suscribió entre octubre de 1810 y julio de 1811. Por liderar la revolución de independencia, fue convertido en la persona más vilipendiada por parte de la clerecía de la Iglesia católica, la cual lo excomulgó, y por el poder virreinal que, al apresarlo, lo pasó por la armas.

\section{Análisis de la Primera proclama formal del Grito de Dolores}

Para fundamentar la identificación de Miguel Hidalgo como un ilustrado consumado, tomo el documento intitulado Primera proclama formal del Grito de Dolores donde vertió alguno de los postulados ideológico-políticos formulados en su convocatoria al inicio de la lucha por la independencia de México el 16 de septiembre de $1810 .{ }^{8} \mathrm{La}$ autenticidad del documento está probada y él mismo confirmó algunas de las ideas allí planteadas en su declaración ante el Tribunal Militar en 1811, cuando fue apresado. ${ }^{9}$ La Primera proclama formal del Grito de Dolores carece de fecha y rúbrica, cuya copia manuscrita, original de la época, se encuentra resguardada en el Archivo General de la Nación de México. Su contenido recrea el discurso de Miguel Hidalgo del 16 de septiembre de 1810, dado en la Iglesia de Dolores, para exhortar al inicio de la lucha de independencia, acción que ha sido mitificada desde el siglo XIX como Grito de Dolores, el cual se celebra oficialmente el 15 de septiembre, a las 23:00 horas, en todo México y en los países donde se encuentren mexicanos. Supongo que fue redactado por Miguel Hidalgo a los pocos días de iniciada la lucha de independencia para clarificar los argumentos con los cuales justificar la empresa tan arriesgada y trascendental que motivó, en virtud del curso que estaban tomando los acontecimientos. Sobra decir que la Primera proclama es un documento combativo cuyos destinatarios son los oriundos de Nueva España, sin importar diferenciación social, para integrarlos a la lucha armada contra el mal gobierno, los españoles y europeos avecindados.

El análisis de las ideas expuestas en este documento prueba sus ideas ilustradas, las cuales pueden ampliarse con otros textos que suscribió como Generalísimo de las Armas Americanas. Para contar con otras fuentes con las cuales los interesados puedan contrastar, complementar o cuestionar esta concepción ilustrada de Miguel Hidalgo, me parece pertinente mencionar otros documentos que avaló o suscribió durante los tres meses siguientes al inicio de la gesta independentista, pero que ahora no son motivo de este estudio: 1) Primer Bando a favor de la abolición de la esclavitud, mandatado al Intendente de Valladolid, José María de Ansorena, del 19 de octubre de 1810; 2) Manifiesto refutando las acusaciones del Tribunal de la Inquisición, Valladolid, del 16 de noviembre de 1810; 3) Plan de Gobierno Americano, entregado a José

8 Este documento aparece publicado en facsímil como "Miguel Hidalgo, 'Primera proclama formal del Grito de Dolores", en Insurgencia y República Federal, 1808-1824. Documentos para la historia del México Independiente, ed. Ernesto Lemoine (3a edición, México, Miguel Ángel Porrúa, 1995), 77-80, el cual empleo para realizar este análisis. Una copia manuscrita, original de la época, sin fecha ni rúbrica, se encuentra en el Archivo General de la Nación, Ramo Operaciones de Guerra, t. 936, ff. 158-159.

9 Documento \# 59 “Hidalgo: 'Acordamos dar el grito”, en Tarsicio García Díaz, ed., Independencia Nacional I. Antecedentes-Hidalgo, (2a edición, México: UNAM, 2005), 254-256. 
María Morelos y suscrito por este en Aguacatillo, fechado el 16 de noviembre de 1810; 4) Proclama a la Nación Americana, Guadalajara, del 21 de noviembre de 1810; 5) Decreto a favor de los indios, Guadalajara, difundido el 5 de diciembre de 1810; 6) Decreto a favor de las castas, Guadalajara, firmado el 6 de diciembre de 1810, y 7) Manifiesto donde propone la creación del Congreso Nacional, Guadalajara, de fecha 15 de diciembre de 1810.

La revisión del contenido del documento en cuestión me permite identificar catorce ideas principales donde se desgranan los argumentos a favor de la lucha por la independencia y dos ideas que puedo considerar como secundarias, sólo porque no se vuelven a desarrollar en los escritos que he enumerado o porque simplemente constituyen una mera relación de los lugares del itinerario de las fuerzas insurgentes.

El análisis consiste en enumerar cada idea rectora expresada sintéticamente; a continuación, transcribo las palabras de Miguel Hidalgo para sustanciar dicha ideas y termino con los comentarios o explicaciones personales.

Libertad política. Para probar este planteamiento cito a Hidalgo: "El sonoro clarín de la libertad política ha sonado en nuestros oídos".$^{10}$ Por estrategia política, la diferencia de la libertad moral que Miguel Hidalgo concibe como libertinaje, puesta en práctica por los "inocuos franceses" y cultivada en tierras americanas por los afrancesados, que han actuado irreligiosamente, poniendo en moda la falta de respeto a Dios, a las imágenes religiosas, a los sacerdotes, y adoptando costumbres extravagantes. ${ }^{11}$

Como se observa, Miguel Hidalgo justifica el inicio de la lucha por la libertad política, exenta de la influencia de los filósofos de la Ilustración y de la Revolución francesa, pero a la vez se deslinda de europeos avecindados y de los americanos con evidentes conductas inmorales.

Contra gobernantes, explotadores y opresores. Miguel Hidalgo suscribe: “La libertad política de que os hablamos, es aquella que consiste en que cada individuo sea único dueño del trabajo de sus manos y el que deba lograr lo que lícitamente adquiera para asistir a las necesidades temporales de su casa y familia; la misma que hace que sus bienes estén seguros de las rapaces manos de los déspotas que hasta ahora nos han oprimido, esquilmándonos hasta la misma sustancia con gravámenes, usuras y gabelas continuadas". ${ }^{12}$

Miguel Hidalgo considera la denuncia contra el dominio de los europeos, de los gobernantes dedicados a garantizar y promover la explotación y opresión a lo largo de la etapa virreinal, prueba irrefutable de la inspiración de la lucha por la libertad política, la cual acabaría con tal sumisión, al cambiar a los gobernantes, y así garantizar la prosperidad de los americanos mediante el libre usufructo de su fuerza de trabajo.

Exaltación de lo americano. Miguel Hidalgo diagnostica las “... riquísimas venas del vasto cuerpo del Continente Americano; es decir, esas masas enormes de plata y oro de que a costa de mil afanes y con peligro de vuestras vidas preciosas estáis sacando hace tres siglos para saciar la codicia de vuestros opresores...". ${ }^{13}$

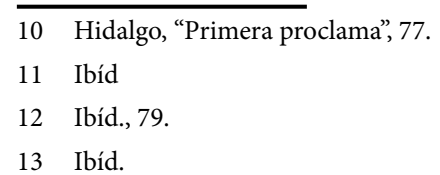


El pensamiento criollista apeló recurrentemente a su derecho al goce de las riquezas del territorio americano al grado de tomarlo como fuente del nacionalismo y, en consecuencia, argumento central contra la hegemonía de los españoles europeos y los beneficios que obtenían; ${ }^{14}$ de modo que debía ponerse fin a los trescientos años de la explotación ilimitada de los recursos naturales. Los argumentos de Miguel Hidalgo expresan paradigmáticamente la ideología de los criollos, pero también un atisbo: radiografiar la explotación de una nación a otra y su lucha para suprimirla.

Promoción de la agricultura. Miguel Hidalgo identifica que “...con gran gusto y desahogo cultivéis aquella ciencia que es el alma del mundo político mercantil y el muelle o resorte que pone en movimiento la gran máquina de nuestro globo, cual es la agricultura, sin el penoso afán de pagar las insoportables rentas que de mucho favor se os han exigido. Porque, decid, ¿habéis hasta ahora disfrutado por una sola vez los placeres del campo sin la zozobra de esperar al que viene a cobraros las rentas de las tierras que trabajáis?". ${ }^{15}$

Sustentar la riqueza de la nueva nación en la producción de la tierra pone de manifiesto, en la argumentación de Hidalgo, la convocatoria a participar en la lucha por la independencia con propósitos muy concretos, caros a los sentimientos de los trabajadores, mayoritariamente, del campo, en ese entonces. La liberación que conseguirían los novohispanos estribaría en beneficiarse al recuperar la tierra para usufructuarla y así garantizar la prosperidad individual y social.

Expulsar a los españoles peninsulares. Exige Miguel Hidalgo: “... con vuestras manos los unos y con vuestras oraciones los otros, acudías a ayudarnos a continuar y conseguir la grande empresa de poner a los gachupines en su madre patria, porque ellos son los que con su codicia, avaricia y tiranía se oponen a vuestra felicidad temporal y espiritual" ${ }^{16}$

La causa de los males de la sociedad novohispana las identificó el pensamiento criollista en el dominio de los españoles peninsulares; por eso, Miguel Hidalgo expresa que sólo la participación de todos los americanos, con su intervención directa en la lucha o con el apoyo espiritual, es que se podrá acabar con la opresión. Incluso, identifica la existencia de una cultura del mal promovida por los peninsulares: "El doblez de sus tratos y ventajosos proyectos de todo género, ha hecho que el engaño, el dolo y la mentira ande en boca de todos y que la verdad casi casi haya desaparecido de nuestro suelo" ${ }^{17}$ Consecuentemente, el triunfo de la lucha de independencia se consumaría con la expulsión de los españoles peninsulares toda vez que acabaría con la dependencia colonial y las inmoralidades.

Exaltación y defensa de la vida. Miguel Hidalgo es enfático en aclarar que la lucha para expulsar a los españoles peninsulares no tiene el propósito de acabar con sus vidas: "No penséis por esto que nuestra intención es matarlos; no, porque esto se opone diametralmente a la Ley Santa que profesamos. Ella nos prohíbe y la humanidad se estremecería de un proyecto tan horroroso, al ver que unos cristianos, cuales somos nosotros, quisiésemos manchar nuestras manos con la sangre humana". ${ }^{18}$

\footnotetext{
14 Para profundizar este tema, recomiendo Alberto Saladino García, "El americanismo de los independentistas como fuente de nacionalismo", Cuadernos Americanos 2, no. 136 (2011): 87-98.

15 Hidalgo, "Primera proclama", 77.

16 Ibid., 78.

17 Ibíd.

18 Ibíd.
} 
Ciertamente, Miguel Hidalgo ampara sus argumentos en el ideal cristiano, pero también como parte del sentido común, de todas las sociedades, de identificar a la vida como el principal valor de la humanidad, a defender y promover. Su compromiso religioso y su actitud racional reflejada en la argumentación del padre de la patria mexicana evidencia su humanismo.

Uso de la violencia sólo por resistencia. Refiriéndose a los españoles peninsulares suscribe: "A ellos les toca, según el plan de nuestra empresa, no resistir a una cosa en que no se les hace más agravio que restituirlos a su suelo patrio y nosotros defenderemos con nuestras armas en caso de forzosa defensa" ${ }^{19}$

Esta posición la puso en práctica como parte de los principios de la guerra, pero como era de esperarse, la mayoría de ocasiones encontró fiera resistencia, lo cual motivó batallas sangrientas, con miles de muertos. Todo ello sucedió por el enfrentamiento de posiciones imposibles de conciliar, unos defendiendo sus fueros y otros luchando por suprimirlos para obtener mejores condiciones de existencia.

Criollos, destinatarios principales de su arenga. Cito: "Aliento, pues, criollos honrados. Aliento. La empresa ya está comenzada; continuémosla... No déis oídos a las horrísonas voces de los que han pretendido espantaros y armaros contra nosotros, diciendo que venimos destruyendo nuestra sagrada religión católica" ${ }^{20}$

El sector social que representa y expresa sería el beneficiario indiscutible del triunfo de su lucha, motivo por el cual lo erige en destinatario principal de su arenga, amparado en dos planteamientos: a) concitar su participación en la lucha, de apoyarla sin dobleces hasta la victoria y b) advertir de la contracampaña ideológica que padecía por parte de los poderes político y religioso, los cuales explotaron en todo lo que pudieron la fe religiosa contra su convocatoria independentista.

Apela a la ayuda de Dios y se manifiesta defensor de la religión católica. En defensa de su supuesta acción destructiva del catolicismo, exclama: “Es ... una falsedad sacrílega ... Los templos han sido venerados, las vírgenes respetadas...". ${ }^{21}$

Señala que el buen inicio de la lucha por la independencia y de su éxito es consecuencia del apoyo del "brazo poderoso de nuestro Dios y Señor", ${ }^{22}$ y recurrentemente apunta que su conducta se circunscribe al respeto de la religión católica y de su promoción. Esta posición da cuenta de la claridad de Miguel Hidalgo acerca de la radical lucha ideológica que empezaba a enfrentar y, para el efecto, recurrió a floridas argumentaciones e informaciones para combatir los cuestionamientos y las descalificaciones relativas a su indiscutible religiosidad católica.

A favor del rey Fernando VII. Más aún, refuta: “También nos dirían que somos traidores al rey y a la patria; pero vivid seguros de que Fernando séptimo ocupa el mejor lugar en nuestros corazones y que daremos pruebas de lo contrario convenciéndolos a ellos de intrigantes y traidores. Por conservarle a nuestro rey estos preciosos dominios y el que por ellos fueran

\begin{tabular}{ll}
\hline 19 & Ibíd. \\
20 & Ibíd. \\
21 & Ibíd., 78-79. \\
22 & Ibíd., 78-79.
\end{tabular}


entregados a una nación abominable, hemos levantado la bandera de la salvación de la patria".$^{23}$

Insisto en señalar como estrategia de los insurgentes la justificación de que su lucha tenía el propósito de resguardar las posesiones ultramarinas del rey Fernando VII, apresado por el ejército francés, lo cual da cuenta de la búsqueda de mayor consenso entre los propios regnícolas y de los americanos con su invocación del amor a la patria. Ciertamente, el foco de la lucha siempre lo orientó a acabar con el dominio de los españoles peninsulares en virtud de la exclusión de los criollos de los poderes político y religioso. En consecuencia, su lucha ideológica de conjuntar la figura del rey y el amor patrio le permitió buscar mayor consenso para concretar los propósitos de su lucha.

Independencia del ejército napoleónico y de los afrancesados. Revira sobre las acusaciones de influencias externas: "Aquél que os dijere que somos emisarios de Napoleón, temed mucho el que sea verdad lo contrario, esto es, que él, ese mismo que lo llegue a decir, lo sea en realidad y mucho más si es europeo, porque nosotros jamás hemos faltado ni somos capaces de tener conexión con ese tirano emperador". ${ }^{24}$

La claridosa y contundente argumentación de Miguel Hidalgo para combatir ideológicamente las más extravagantes acusaciones de que fuerzas extranjeras respaldaban su accionar lo lleva a revertirlas a quienes lo acusaban en Nueva España y a deslindarse del mismo accionar del emperador francés, para respaldar la legitimidad de su lucha a favor de la independencia y, desde esta posición, rechazar el intervencionismo napoleónico, gota que había derramado el vaso para el florecimiento de los sentimientos criollos de acabar con el dominio de los españoles peninsulares.

Amparo guadalupano. Escribió Miguel Hidalgo “... hemos levantado la bandera de la salvación de la patria poniendo en ella a nuestra universal patrona, la siempre Virgen María de Guadalupe. Ella nos ha de sostener y ayudar en este gran proyecto, dará esfuerzo a los débiles, esperanza a los tímidos y valor a los pusilánimes; disipará de las cabezas de muchos los angustiados pensamientos que le atormentan el alma, considerando la arduidad de la empresa, y facilitará su ejecución". ${ }^{25}$

Conocedor de que el elemento aglutinador de los novohispanos lo constituía el catolicismo, del cual Miguel Hidalgo fue un ferviente creyente, practicante y partidario, decidió amparar su lucha en el símbolo de mayor credibilidad espiritual forjado por esta religión en la Nueva España, por lo cual decidió tomar el estandarte de la Virgen de Guadalupe del convento de Atotonilco para encomendarle a todos los participantes de la independencia y amparar en ella el inminente triunfo.

Unidad para luchar por causa justa. Demandó Miguel Hidalgo: “Unámonos a sostener una causa a nuestro parecer justa y santa, como lo es mantener ilesa nuestra santa religión, la obediencia a nuestro romano pontífice y a nuestro rey y señor natural, a quien hemos jurado obedecer, respetar su nombre y leyes, cuidar de sus intereses [y] perseguir a cuantos se opongan a ello". ${ }^{26}$

\footnotetext{
23 Ibíd.

24 Ibíd., 80.

25 Ibíd., 79

26 Ibíd., 80.
} 
La insistencia en que la lucha iniciada por los insurgentes era una empresa justa y santa resume la preocupación de mostrar la nobleza de sus acciones y, sobre todo, de ubicar como propósito de ella la defensa de la religión, así como para mantener la obediencia al papa y al rey, con todo lo que expresa elocuentemente esa estrategia de legitimar sus actos y, por ende, la convocatoria para la participación de todo mundo en la lucha.

Arenga. Finaliza la Proclama del Grito de Dolores sintetizando su argumentación en los términos siguientes: “¡Viva la religión católica! ¡Viva Fernando VII! ¡Viva la patria! Y ¡Viva y reine por siempre en este Continente Americano nuestra sagrada patrona, la Santísima Virgen de Guadalupe! ¡Muera el mal gobierno! Esto es lo que oiréis decir de nuestra boca y lo que vosotros deberéis repetir". ${ }^{27}$

En efecto, la arenga es la expresión magistral en la que Miguel Hidalgo encarnó las expectativas de los criollos; por eso se erigió en su más importante vocero y guía, de modo que con ella legitimó el inicio de la lucha por la independencia.

Con respecto a las ideas secundarias contenidas en esta Proclama, me parece que dos resultan evidentes en tanto hacen una crónica de la incipiente lucha insurgente y presentan un destello de la preocupación social que concitaría.

Relación de pruebas sobre el proceder pacífico de su lucha. Miguel Hidalgo demanda: "Preguntad a Zelaya, San Miguel, Irapuato, etcétera, donde nos han recibido de paz; e interrogad a Guanajuato, que es la única ciudad donde encontramos resistencia y donde operamos no con todos los rigores de la guerra que nos presentaron...". ${ }^{28}$

Una preocupación reiterativa del discurso de Miguel Hidalgo consistió en propalar la idea de que la lucha iniciada no sólo era justa, sino convincente y contraria a toda imagen difundida de destructiva y violenta. Por eso, su interés en informar acerca de su itinerario.

Importancia de la educación. Miguel Hidalgo planteó visionariamente: “La educación, las virtudes morales de que sois susceptibles, el cultivo de vuestros despejados talentos para ser útiles a vosotros mismos y vuestros semejantes, aún se hallan en el caos de la posibilidad. Reflexionad un poco sobre esto y hallaréis el gran bien que se os prepara...".29

En efecto, habló con conocimiento de causa pues tuvo un diagnóstico preciso de la precariedad del estado de la educación, como lo había interpretado desde su juventud y en el desempeño de sus importantes actividades académicas. El reconocimiento de su significado lo expuso como argumento para concitar la participación en esta lucha, al otorgar en su proyecto de nación un papel fundamental a la educación para mejorar la vida de los habitantes.

\footnotetext{
27 Ibíd.

28 Ibíd.

29 Ibíd.
} 


\section{CONCLUSIÓN}

Miguel Hidalgo tuvo la creatividad para dialectizar sus ideas y enfrentar situaciones embarazosas como, por ejemplo, concitar a la lucha contra el mal gobierno virreinal y justificarla como testimonio de su conducta regnícola para evitar que la Nueva España pasara a manos de un tirano -Napoleón $3 / 4$, a una nación extranjera. Lo cierto es que este tipo de razonamientos sólo fue una parte de su estrategia política, porque nunca abandonó su principal motivación: establecer un gobierno de americanos.

Igualmente, si bien no reprodujo algunas categorías del pensamiento de la Ilustración, invocó sus contenidos y los intentó llevar a la práctica al promover la soberanía popular, cuyos antecedentes lo constituyeron los planteamientos de Francisco de Azcárate, Francisco Primo de Verdad, Jacobo de Villaurrutia y el sacerdote mercedario Melchor de Talamante, en 1808. Claro que no mencionó a Juan Jacobo Rousseau, pero su lucha por recuperar para los americanos sus derechos legítimos y su gobierno al depositar en ellos la legitimidad de la autoridad y del poder, son pruebas fehacientes de su claridad ideológica de avanzada.

En abono a mis puntos de vista señalo a continuación tres tipos de conclusiones: a)el conocimiento y promoción de algunos valores caros a la Ilustración; b) la existencia de planteamientos contradictorios que exhiben a Miguel Hidalgo como un hombre de transición entre dos época, y c) la originalidad con la cual justificó la génesis de la lucha por la independencia.

Miguel Hidalgo usó como justificantes en su arenga del inicio de la lucha de independencia valores propalados por la Ilustración, por ejemplo: propugnar la consecución de la libertad política de Nueva España; apelar a la exaltación y defensa de la vida; invocar la justicia como objetivo de la lucha para acabar con las exclusiones sociales; concebir a la educación como medio para lograr la redención humana; promover actividades productivas, en particular la agricultura para garantizar la satisfacción de las necesidades de los novohispanos. Todo ello posible si los americanos se unían a la lucha independentista, pues su triunfo mejoraría la forma de vida mediante la implantación de un nuevo gobierno, conducido este por los propios americanos.

Esa claridad de principios expuestos por Miguel Hidalgo que permiten tenerlo como promotor de los valores de la modernidad no impide situar otras de sus ideas como contradictorias, explicable por ser un hombre situado en el vértice de dos épocas, una que estaba por fenecer y otra nueva que se buscaba construir. Entre los planteamientos de su Proclama del grito de Dolores que evidencian esta posición ambivalente puedo referir la peculiar diferenciación que estableció entre libertad política y libertad moral, donde identifica a ésta con libertinaje y aquélla la asocia a la responsabilidad de los actores públicos; su supuesta lucha pacifista que debido a la resistencia encontrada por los españoles peninsulares a rendirse dio pauta a una guerra devastadora; la apelación recurrente a la ayuda de Dios para la consecución de sus propósitos y su declarada fe de defensor de la religión católica, pero que con sus actos puso en cuestión la estructura y jerarquía clerical, por lo que ésta lo excomulgó; y lo más insólito de esa posición insostenible estriba en su argumentación de que inició su lucha para defender la soberanía del rey Fernando VII, cuando la motivación central consistió en propugnar un gobierno de los criollos, de los americanos.

Con dichas reflexiones espero no dejar la impresión de que Miguel Hidalgo fue mero corifeo de la Ilustración o un hombre contradictorio incapaz de contar con una perspectiva propia, 
pues desde mi punto de vista resultó totalmente original en sus ideas y obviamente valeroso en sus acciones. El padre de la patria mexicana no fue un hombre sólo reactivo y desprovisto de cultura, sino una persona vanguardista en el campo intelectual, producto del ambiente de renovación existente en los últimos sesenta años de vida colonial, y líder político con ideas preclaras y aventajadas que supo encarnar las expectativas de la mayoría de la población y particularmente del sector al que pertenecía, el de los criollos. De modo que su ideario fue producto de sus aprendizajes y de las condiciones socioculturales señaladas, los cuales dialectizó y le permitieron forjar propuestas que canalizó mediante su lucha por la independencia.

La cuestión de la exclusión de los americanos de los poderes dominantes la elevó al plano de principal exigencia de la lucha que emprendió y que lo hicieron declarar como propósito de la independencia acabar con el mal gobierno, cuyo cometido se reducía a expoliar la riqueza que legítimamente producían y les pertenecía a los americanos con todo tipo de impuestos.

Pero la mayor relevancia de su discurso consiste en haber identificado el atisbo de que los americanos, en particular los indios, las castas y quienes vendían su fuerza de trabajo, eran sometidos a explotación despiadada por parte de los españoles peninsulares, pero que con el triunfo de la lucha independentista podría suprimirse la explotación del hombre por el hombre, del pueblo americano por el pueblo español. Esta cuestión marca un verdadero hito, un hecho distintivo de la lucha de independencia que no se redujo a motivaciones político-ideológicas, sino incorporó una cuestión central de carácter socioeconómico. Por la originalidad del pensamiento y la acción de Miguel Hidalgo debe ser ubicado como un verdadero revolucionario y en consecuencia la lucha que encabezó identificarse no como una guerra, la de independencia, sino como una verdadera revolución, la de Independencia.

Así Miguel Hidalgo trascendió la perspectiva criollista de luchar sólo por el reclamo de expulsar a los españoles peninsulares del poder para instalarse en su lugar, al plantear propuestas orientadas a la refundación de la sociedad, donde el producto del trabajo de los americanos les aportara los elementos suficientes para gozar de condiciones de vida justa y por ello le otorga a la educación una función específica de redención.

También en ese documento existe una doble insistencia en desmarcarse de todo tutelaje como evidencia de los propósitos libertarios que guían su acción revolucionaria de concretar la independencia de Nueva España al rechazar toda influencia extranjera o cualquier vínculo con el ejército napoleónico, mostrándolo con su acerba crítica a los afrancesados novohispanos. Fue un hombre radicalmente independiente y, por ende, con suficiente autoridad moral para encabezar la lucha por la independencia de Nueva España.

Otro de los rasgos de su sensibilidad política estribó en explotar el culto guadalupano en los sectores mayoritarios del pueblo, entre los americanos, por lo que no dudó en amparar su lucha en Dios y materializarlo mediante el uso del estandarte de la Virgen Guadalupana. Dio origen al guadalupanismo como referentes de identidad de la nación por nacer.

En fin, Miguel Hidalgo coadyuvó a la construcción de las bases de la nación mexicana a través de su lucha, de la creación de valores identitarios y al establecer la categoría de pueblo americano como fundamento de la soberanía.

Por ende considero que la Primera proclama formal del Grito de Dolores, documento pasado por alto por algunos de los estudiosos del padre de la patria, e ignorada por la inmensa mayoría 
de mexicanos, debe considerarse como el texto que mejor retrata los fundamentos teóricos, las ideas, el pensamiento y el proyecto político que guió la vida revolucionaria de Miguel Hidalgo. Con base en él sustento que fue un ilustrado consumado porque trastocó un orden de casi trescientos años. Nada menos que actuó como verdadero revolucionario al conjuntar acción y teoría de la modernidad.

\section{REFERENCIAS}

Alamán, Lucas. "Semblanza de los iniciadores de la independencia". En Antología de lecturas de historia de México, ed. Martha Celada Castillo y Ruvalcaba. México: Universidad Nacional Autónoma de México, 1995, 65-67.

García Díaz, Tarsicio y Margarita Bosque Lastra. Independencia nacional. Fuentes y documentos. Memorias 1808-1810. México: Universidad Nacional Autónoma de México, 2007.

Guzmán Pérez, Moisés. Miguel Hidalgo y el gobierno insurgente en Valladolid. Morelia: Universidad Michoacana de San Nicolás de Hidalgo, 1996.

Herrejón Peredo, Carlos. Hidalgo antes del Grito de Dolores. Morelia: Universidad Michoacana de San Nicolás de Hidalgo, Biblioteca de Nicolaítas Notables Nº 46, 1992.

Herrejón Peredo, Carlos. Hidalgo, maestro, párroco e insurgente. Madrid: Fondo Cultural Banamex/Clío/Aeroméxico, 2011.

Hidalgo, Miguel, "Primera proclama formal del Grito de Dolores". En Insurgencia y República Federal, 1808-1824. Documentos para la historia del México Independiente, ed. Ernesto Lemoine. México: Miguel Ángel Porrúa, 1995, 75-80.

Hidalgo, Miguel, "Acordamos dar el grito", Documento \# 59. En Independencia Nacional I. Antecedentes-Hidalgo, ed. Tarsicio García Día, 2a edición. México: UNAM, 2005, 254-25.

Moreno, Rafael. La filosofía de la Ilustración en México y otros escritos. México: Universidad Nacional Autónoma de México, 2000.

Navarro B., Bernabé. Cultura mexicana moderna en el siglo XVIII. México: Universidad Nacional Autónoma de México, 1983.

Rovira Gaspar, María del Carmen. Una aproximación a la historia de las ideas filosóficas en México. Siglo XIX y principios del XX. México: Universidad Nacional Autónoma de México, 1997.

Saladino García, Alberto. "Repercusión de las ideas ilustradas en la Revolución de Independencia". Cuadernos Americanos 2, no. 124 (2008): 83-88.

Saladino García, Alberto. "El americanismo de los independentistas como fuente de nacionalismo". Cuadernos Americanos 2, no. 136 (2011): 87-98. 


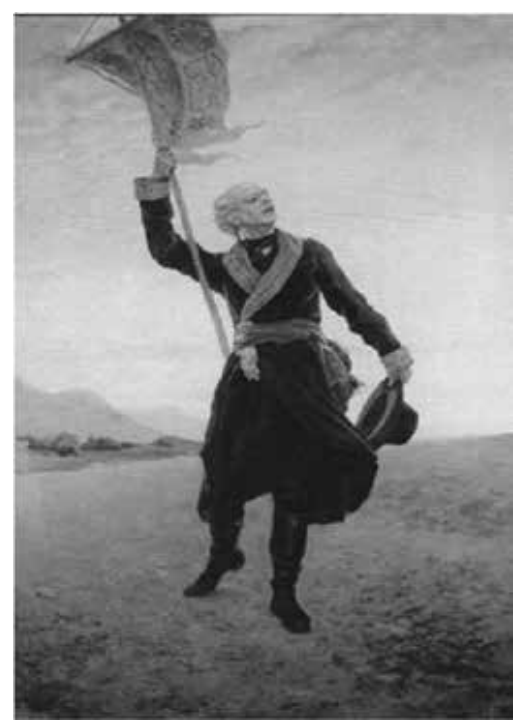

RETRATO DE MIGUEL HIDALGO Y COSTILLA

Fuente: realizado por Antonio Fabrés (1854-1938). Actualmente se localiza en Palacio Nacional, Ciudad de México. Tomado de Tarsicio García Díaz y Margarita Bosque Lastra, Independencia nacional. Fuentes y documentos. Memorias 18081810. México: Universidad Nacional Autónoma de México, 2007.

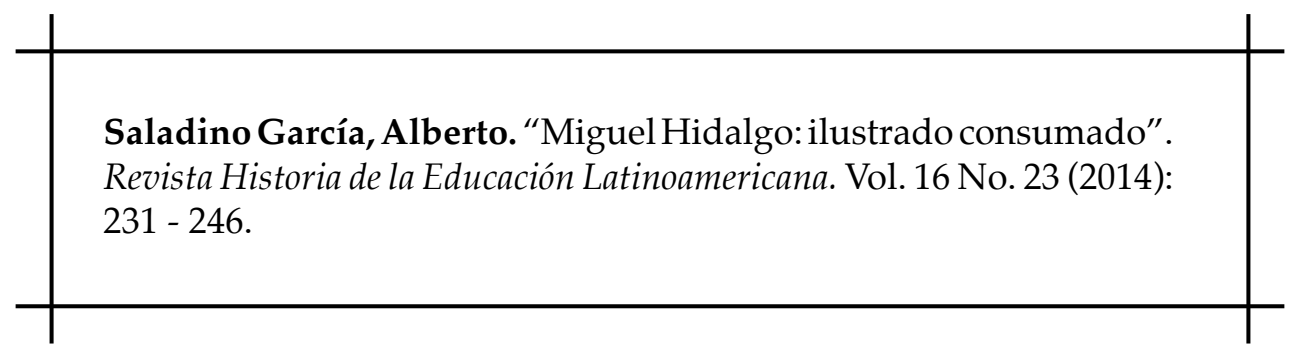


